\title{
Peran Institusi Lokal Dalam Pembentukan Habitus Siaga dan Pengembangan Mitigasi Bencana di Kawasan Gunung Kelud Kabupaten Kediri
}

\author{
Windiani $^{1}$, I.B. Wirawan ${ }^{2}$ dan $_{\text {Sutinah }}{ }^{3}$ \\ ${ }^{1}$ Departemen Studi Pembangungan- FBMT, Institut Teknologi Sepuluh Nopember. Surabaya, E-mail: \\ windianiits@gmail.com \\ 2,3 Jurusan Sosiologi, FISIP, Universitas Airlangga, Surabaya
}

Diterima: 12 Juli 2019

Direview: 26 Juli 2019

Diterbitkan: 31 Juli 2019

Hak Cipta @ 2017 oleh Penulis (dkk) dan Jurnal Sosial Humaniora (JSH)

*This work is licensed under the Creative Commons Attribution International License (CC BY 4.0). http://creativecommons.org/licenses/by/4.0/
Subject Areas: Social

\begin{abstract}
This study aims to explore the role of local institutions in the establishment of preparedness habitus and the development of disaster mitigation in Mount Kelud area of Kediri Regency using the structural-constructivist approach of Pierre Bourdieu. This research is qualitative research in nature so that the data collection is conducted by participant observation, document tracking, and indepth interview. The results showed that local institutions that play a role in the formation of disaster prepared habitus and mitigation development in the Mount Kelud area are formal institutions e.g. BPBD of Kediri, District and Village, and informal institutions namely the Jangkar Kelud Community and the Village Disaster Preparedness Team. The research also found that collaborative roles between leaders and local leaders have contributed greatly to the formation of disaster preparedness habitus for residents of Mount Kelud Slopes. In the formation of preparedness habitus and disaster mitigation leaders and local leaders use the knowledge and local wisdom as capital value to develop the attitude of life "Harmony with Mount Kelud", and the principle of life 'Sitik Edang.
\end{abstract}

Keywords : Roles, Local Institutions, Habitus, Disaster Preparedness, Disaster Mitigation

\section{Pendahuluan/Latar Belakang}

Studi Ilmu Sosial dalam bidang kebencananaan berkembang pesat di berbagai negara termasuk di Indonesia dalam satu dasawarsa terakhir. Berbagai perspektif dan pendekatan dikembangkan antara lain dalam bidang Antropologi (Smith \& Hofman, 2004), bidang Sosiologi (Lalone, 2012), Geografi (Wisner, 2004; Kelman, 2008). Di Indonesia kajian tentang kebencanaan dikembangkan antara lain; Ahimsa Putra Indiyanto, ed, (2012);
Sirimarok (2013) Sartohadi, dkk (2014), Humaidi (2015), Pramono (2016), Arifin dan Chusairi (2015), Devy, dkk (2017). Meski sudah dikaji secara luas, namun studi yang mengeksplorasi peran institusi lokal dalam pengelolaan bencana terutama dalam pembentukan habitus siaga dan mitigasi di kawasan rawan bencana masih terbatas sehingga dipandang penting, menarik dan membuka peluang baru untuk dilakukan. Studi ini bertujuan mengekplorasi peran institusi lokal (formal dan informal) dan dinamika dalam pengelolaan bencana terutama dalam upaya 
pembentukan habitus siaga dan mitigasi bencana di kawasan gunung Kelud Kabupaten Kediri pasca erupsi tahun 2014. Studi ini menggunakan pendekatan etnografi dengan perangkat konseptual Habitus, Ranah dan Modal dari Pierre Bourdieu serta konsep bencana dan pengelolaanya dari kajian terdahulu yang relevan.

Ada beberapa alasan mengapa studi ini dipandang menarik dan penting dalam konteks kekinian: Pertama, kejadian bencana dalam satu dasawarsa semakin meningkat baik skala maupun intensitasnya yang menimbulkan berbagai kerusakan dan korban jiwa. Berdasarkan laporan World Risk Report (2012) dari tahun 2002 hingga 2011 telah terjadi 4.130 bencana di seluruh dunia yang mengakibatkan lebih dari 1 juta orang meningggal dan kerugian material yang mencapai US\$ 1,195 triliun. Di Indonesia, berdasarkan data Litbang KOMPAS (2016), kerugian ekonomi akibat bencana pada periode 2004-2013 mencapai Rp. 162,8 trilyun. Lima tahun terakhir dampak ekonomi bencana rata- rata Rp. 30 trilun per tahun. Menurut BNPB (2016) selama ini pembangunan di Indonesia belum memasukkan variabel pengurangan risiko bencana. Meski sejak tahun 2014 telah memiliki rencana induk, namun belum berjalan efektif dan pengurangan risiko bencana (mitigasi) belum terintegrasi dalam program pembangunan (Kompas, 14 Desember 2016).

Kedua, secara geografis posisi Indonesia yang terletak di antara lempeng Erusia dan lempeng Australia serta berada di jalur ring of fire (cincin api) telah menempatkan Indonesia sebagai negara rawan bencana alam di dunia. Sebagian besar wilayah Indonesia, memiliki ancaman bencana gempa bumi, tsunami, letusan gunung berapi, banjir, dan tanah longsor.

Merujuk data BNPB, selama tahun 2016, jumlah bencana tahun 2016 mencapai 2.151 kejadian, tertinggi dalam satu dekade terakhir sebagaimana yang diilustrasikan dalam tabel 1 .

Tabel 1. Korban dan Kerusakan akibat Bencana (Sampai November 2016)

\begin{tabular}{|c|c|c|c|c|c|c|c|}
\hline \multicolumn{2}{|c|}{ Jumlah Kejadian } & \multicolumn{2}{|c|}{ Korban } & \multicolumn{4}{c|}{ Kerusakan (ribu rumah) } \\
\cline { 3 - 8 } & $\begin{array}{c}\text { Hilang dan } \\
\text { meninggal } \\
\text { (jiwa) }\end{array}$ & $\begin{array}{c}\text { Luka dan } \\
\text { mengungsi } \\
\text { (juta jiwa) }\end{array}$ & Berat & Sedang & Ringan & Terendam \\
\hline 2014 & 1.967 & 622 & 2.83 & 20.1 & 6.1 & 29.5 & 530.4 \\
\hline 2015 & 1.677 & 259 & 1.22 & 5.2 & 3.8 & 16.2 & 180.3 \\
\hline 2016 & 2.171 & 567 & 2.77 & 5.7 & 6.9 & 23.6 & 286.9 \\
\hline
\end{tabular}

Sumber: Litbang Kompas, 14 Desember 2016

Di propinsi Jawa Timur, hampir sebagian besar merupakan daerah rawan bencana. Berdasarkan data yang dilansir Badan Penanggulangan Bencana Daerah (BPBD), terdapat 32 dari 38 Kabupaten di Jawa Timur (2016) masuk dalam wilayah rawan bencana banjir, longsor, gempa dan tsunami, ditambah 7 gunung berapi aktif di Jawa Timur yang sewaktu waktu meningkat aktivitasnya, yaitu gunung
Kelud di Kabupaten Kediri-Blitar-Malang-Batu, gunung Arjuno-Welirang di Malang, gunung Bromo di Probolinggo, gunung Semeru di Lumajang, gunung Ijen di Banyuwangi, gunung Raung di Jember dan gunung Lemongan di Lumajang

Alasan Ketiga, realitas atas bencana bersifat multidimensional. Pemahaman masyarakat atas bencana, karakteristik sosial budaya, kapabilitas 
institusi lokal, struktur sosial, dan pengetahuan lokal turut menentukan sikap dan respon masyarakat terhadap bencana. Merujuk pemikiran Oliver Smith yang mendefinisikan bencana sebagai perjumpaan antara kerentanan sosial ekonomi suatu masyarakat dan kekuatan destruktif lingkungan alamiah, serta teknologi yang mengakibatkan gangguan pada pemenuhan kebutuhan individual dan sosial (OliverSmith \& Sussane Hofman 2004: 3-4). Ini berarti bahwa banyak faktor yang menyebabkan terjadinya bencana, untuk itu upaya mengatasi bencana, melakukan pencegahan dan pengurangan resiko bencana menuntut keterlibatan berbagai pihak dalam menghadapi bencana.

Di Indonesia, lahirnya Undang-Undang Republik Indonesia No 24 tahun 2007 tentang Penanggulangan Bencana dan PP No 21 tahun 2008 tentang Penyelenggaraan penanggulangan bencana di tanah air telah memberi ruang bagi pengembangan tata kelola bencana berbasis kapasitas lokal. Model pengelolaan ini mensyaratkan keterlibatan bukan saja pemerintah yang direpresentasikan melalui Badan Nasional Penanggulangan Bencana (BNPB), Badan Penanggulangan Bencana Daerah (BPBD), namun juga masyarakat lokal, LSM/NGO, swasta dan pihakpihak yang concern terhadap masalah lingkungan kebencanaan serta pengelolaannya. Dalam konteks kekinian model pengelolaan yang hanya mengandalkan peran tunggal (misalnya hanya pemerintah saja) tidak lagi relevan, mengingat bencana yang terjadi pun bersifat kompleks dan multidimensional, sehingga dibutuhkan peran, tanggung jawab, dan keterlibatan banyak pihak dalam pengelolaannya. Berdasarkan latar belakang yang telah diuraikan, studi ini berupaya mengeskplorasi peran institusi lokal dalam pengelolaan bencana terutama dalam pembentukan habitus siaga dan mitigasi bencana dengan wilayah studi di kawasan Gunung Kelud Kabupaten Kediri pasca erupsi tahun 2014.

\section{Kajian Teoritis}

Kajian ini menggunakan pendekatan konstuktivis strukturalis dari Pierre Bourdieu (1984) sebagai kerangka teori dan metode untuk memahami kompleksitas realitas sosial di wilayah studi dengan perangkat konseptual Habitus, Ranah dan Modal. Dasar pertimbangan menggunakan pemikiran Pierre Bourdieu adalah isu dalam kebencanaan bukanlah realitas yang tunggal, namun kompleks. Peristiwa bencana dan pengelolaannya syarat dengan prosesproses dan dinamika sosial budaya; termasuk dalam pemahaman dan pemaknaan atas bencana, respon masyarakat, serta dinamika dalam pengelolaan bencana terutama di wilayah rawan bencana.

Dalam buku (Habitus X Modal) + Ranah= Praktik, karya Richard Harker, dkk (2009) mengupas pemikiran Pierre Bourdieu tentang Habitus, Ranah dan Modal. Bourdieu (1979: vii) mendefinisikan habitus sebagai "suatu sistem disposisi yang berlangsung lama dan berubah-ubah (durable, transposible disposition) yang berfungsi sebagai basis generatif bagi praktik-praktik yang terstruktur dan terpadu secara objektif" (Harker, dkk, 2009:13). Rumus ini mengganti setiap relasi sederhana antara individu dan struktur dengan relasi antara habitus dan ranah yang melibatkan modal.

Dalam karyanya yang terkenal "La Distingtion" yang diterjemahkan dalam Bahasa Inggris "Distingtion", Bourdieu (1986) menyatakan bahwa habitus merupakan "the mental stuctures through which they apprehend the social world, are esentially the product of an internatialization of the structures of the social world". Habitus dapat 
dipahami secara dialektis-relasional, habitus merupakan hasil internalisasi struktur dunia sosial atau struktur sosial yang dibatinkan yang diwujudkan (Bourdieu, 1986:468).

Menurut Bourdieu, habitus adalah 'strukturstruktur mental atau kognitif" melalui mana orang berurusan dengan dunia sosial. Habitus membimbing aktor untuk memahami, menilai, mengapresiasi tindakan mereka berdasarkan pada skema atau pola yang dipancarkan dunia sosial. Melalui skema-skema demikianlah orang menghasilkan praktik-praktik mereka maupun merasakan dan mengevaluasinya. Secara dialektis habitus "produk internalisasi stukturstruktur" dunia sosial. Habitus memproduksi dan diproduksi oleh dunia sosial. Di satu sisi, habitus adalah suatu 'stuktur yang menstruktur" yakni, ia adalah struktur yang menyusun duina sosial. Di sisi lain, ia adalah suatu 'stuktur yag distrukturkan"; yakni ia adalah stuktur yang disusun oleh dunia sosial. Praktiklah yang menengahi antara habitus dan dunia sosial. Di satu sisi melalui praktiklah habitus diciptakan, di sisi lain dunia sosial diciptakan sebagai hasil dari habitus (Ritzer, 2014:482).

Ranah (Field) oleh Bourdieu diartikan sebagai jaringan relasi antar posisi-posisi objektif dalam suatu tatanan sosial yang hadir terpisah dari kesadaran dan kehendak individual. Ranah merupakan arena kekuatan yang didalamnya terdapat upaya perjuangan untuk memperebutkan sumber daya (modal) dan juga untuk memperoleh akses tertentu yang dekat dengan hierarki kekuasaan. Ranah juga merupakan arena pertarungan di mana mereka yang menempatinya dapat mempertahankan atau mengubah konfigurasi kekuasaan yang ada. Struktur ranahlah yag membimbing dan memberikan strategi bagi penghuni posisi, baik individu maupun kelompok untuk melindungi dan meningkatkan posisi mereka dalam kaiatannya dengan jenjang pencapaian sosial. Apa yang mereka lakukan berdasarkan pada tujuan yang paling menguntungkan bagi prodiuk mereka sendiri. Ranah adalah suatu tipe pasar terbuka yang kompetitif tempat jenis modal (ekonomi, budaya, sosial, simbolik) dipergunakan dan disebarkan (Ritzer, 2014:484-485).

Dalam ranah menuntut individu-individu untuk memiliki modal-modal khusus agar dapat hidup secara baik dan bertahan di dalamnya. Dalam ranah, 'pertarungan' sosial selalu terjadi. Mereka yang memiliki modal dan habitus yang sama dengan kebanyakan individu akan lebih mampu melakukan tindakan mempertahankan atau mengubah struktur dibandingkan dengan mereka yang tidak memiliki modal.

Pengelolaan bencana di kawasan Gunung Kelud dapat dipandang sebagai ranah dan ruang beroperasinya habitus serta reproduksi modal. Dalam ranah tersebut terdapat relasi yang dinamis antar aktor dari istitusi lokal yang terlibat dalam pengelolaan bencana, seperti masyarakat lokal, aparat pemerintah, dan LSM. Masing-masing pihak berusaha menguatkan dan mempertahankan posisinya dengan berbagai strategi. Strategi dalam konteks studi dimaksudkan untuk menjelaskan cara aktoraktor dalam membangun kekuatanya dalam pengelolaan bencana khususnya dalam pembentukan habitus siaga dan mitigasi bencana bencana di kawasan lereng Kelud. Bagaimana strategi yang digunakan dan sumber daya (modal) yang diperjuangkan aktor-aktor dari istitusi lokal yang terlibat dalam membangun habitus siaga dan mitigasi bencana inilah yang perlu diuji secara empiris di lapangan. 


\section{Metode Penelitian}

Penelitian ini merupakan penelitian kualitatif dengan menggunakan pendekatan etnografi (Atkinson, dkk, 2001) untuk mengeskplorasi fenomena sosial budaya yang terjadi di wilayah studi. Penelitian dilakukan di kawasan rawan bencana Gunung Kelud Kabupaten Kediri pasca erupsi tahun 2014. Pegumpulan data dilakukan menggunakan cara: participant obeservation, penelusuran dokumen dan in depth interview terhadap 22 informan yang berasal dari institusi pemeritah daerah; BPBD, Camat, Kepala Desa, Koordiator, dan relawan dari Komuitas Jangkar Kelud, tokoh Masyarakat, tokoh adat, tokoh agama (Islam: NU, Muhammadiyah, Kristen, Hindu) dan warga yang tinggal di sekitar Gunung Kelud.

\section{Hasil Penelitian dan Pembahasan}

\section{Keterlibatan Institusi Lokal Dalam Pengelolaan}

\section{Bencana Di Kawasan Gunung Kelud Kabupaten}

\section{Kediri Pasca Erupsi 2014}

Berdasarkan hasil eksplorasi di lapangan, institusi lokal yang terlibat dalam pengelolaan bencana di kawasan Gunung Kelud Kabupaten Kediri pasca erupsi tahun 2014 meliputi pemerintah daerah yaitu dari Pemerintah Kabupaten Kediri, Komunitas Jangkar Kelud, Tim Siaga Desa dan para relawan dari berbagai organisasi profesi (PGRI), keagamaan (NU, Muhammdiyah, Komuitas Pemuda Kristen, Pemuda Katolik dan Komunitas Hindu) dan kemasyarakatan;
PMR, PMI, Pramuka, karang taruna, PKK dan lainlain. Tugas dan kewenangan pengelolaan bencana oleh pemerintah daerah diselenggarakan oleh Badan Penanggulangan Bencana (BPBD) sebagaimana yang telah diatur dalam UU RI No 24 tahun 2007 Tentang Penanggulangan Bencana, UU No 21 tentang Penyelengaraan Penanggulangan Bencana di Indonesia dan di di tingkat daerah diatur dalam perda masing-masing, seperti di Kediri diatur dalam Perda No 2 tahun 2015 tentang tata kelola Organisasi Penanggulangan Bencana di Kabupaten Kediri.

Dalam pengelolaan bencana di KRB Gunung Kelud pasca erupsi tahun 2014, cenderung mengembangkan pola pengelolaan berbasis sinergitas antar stakeholder yaitu dengan membangun hubungan kerjasama (kolaborasi) dengan institusi lokal yang memiliki komitmen dalam pengelolaan bencana. Pola kolaborasi ini melibatkan para pemangku kepentingan yaitu pemerintah-NGO dan masyarakat dengan aktor-aktor utama (BPBDRelawan Komunitas Jangkar Kelud dan Tim Siaga Desa) dalam tata kelola bencana. Melalui praktik kerjasama-kolaborasi dari institusi lokal yang ada diharapkan dapat menghasilkan sinergitas yang produktif.

Tabel berikut merupakan deskripsi dari keterlibatan institusi lokal baik institusi formal maupun informal yang terlibat langsung dalam pengelolaan bencana di kawasan Gunung Kelud Kabupaten Kediri pasca erupsi tahun 2014. Tabel 2.

Tabel 2. Keterlibatan Institusi Lokal Dalam Pengelolaa Bencana Di KRB Gunung Kelud Pasca Erupsi Tahun 2014

\begin{tabular}{|c|c|c|c|}
\hline No & Institusi Lokal & Nama Institusi & Keterlibatan \\
\hline 1 & Pemerintah & $\begin{array}{l}\text { BPBD } \\
\text { Kecamatan } \\
\text { Pemerintahan Desa }\end{array}$ & $\begin{array}{l}\text { Merumuskan visi pengelolaan bencana dengan melibatkan } \\
\text { berbagai stakeholder dan institusi lokal yang berkecimpung } \\
\text { dalam penanggulangan bencana } \\
\text { Merumuskan dan menetapkan kebijakan penanggulangan } \\
\text { bencana dan penanganan pengungsi dengan bertindak cepat } \\
\text { dan tepat, efisien. }\end{array}$ \\
\hline
\end{tabular}




\begin{tabular}{|c|c|c|c|}
\hline & & & $\begin{array}{l}\text { Melakukan fungsi pengkoordinasian pelaksanaan kegiatan } \\
\text { penanggulangan bencana secara terencana, terpadu dan } \\
\text { menyeluruh. } \\
\text { Memfasilitasi kegiatan yang bertujuan untuk pengurangan } \\
\text { risiko bencana, membangun kesiapsiagaan masyarakat dan } \\
\text { megembangkan mitigasi bencana. } \\
\text { Pemerintah desa elaksanakan menjalankan fungsi koordinasi, } \\
\text { melaksanak dan mengembangkan program kegiatan dalam } \\
\text { pengelolaan bencana di KRB Gunung Kelud. }\end{array}$ \\
\hline 2 & NGO (LSM) & Komunitas Jangkar Kelud & $\begin{array}{l}\text { Memberikan masukan kepada pemerintah agar pengelolaan } \\
\text { bencana dapat bersinergi. } \\
\text { Mendorong pengembangan model pengelolaan berbasis } \\
\text { kolaborasi antar istitusi baik formal maupun non formal. } \\
\text { Menginisiasi dan mendorong pemerintah untuk memperkuat } \\
\text { kelembagaan (institusi) lokal yang ada dengan membangun } \\
\text { jaringan dengan institusi yang memiliki komitmen dalam } \\
\text { pengelolaan bencana mulai level lokal, regional, nasional } \\
\text { hingga global. }\end{array}$ \\
\hline 3 & Masyarakat Lokal & $\begin{array}{l}\text { Tim Siaga Bencana desa, } \\
\text { relawan dari organisasi } \\
\text { masyarakat, tokoh adat, tokoh } \\
\text { agama, organiasi kepemudaaa n }\end{array}$ & $\begin{array}{l}\text { Berpartisipasi dalam kegiatan dalam pendidikan, pelatihan, } \\
\text { simulasi dan kegiatan dalam membangun kesiapsiagaan dan } \\
\text { pengembagan mitigasi } \\
\text { Meyampaikan aspirasi kepada pemerintah dan komuitas lokal } \\
\text { terkait pola pengelolaan yang lebih sesuai dengan kebutuhan } \\
\text { masyarakat. }\end{array}$ \\
\hline
\end{tabular}

Sumber: Hasil in dept interview, 2018

Berdasarkan identifikasi peran institusi lokal dalam pengelolaan bencana, temuan data di lapangan menunjukkan bahwa Komunitas Jangkar Kelud merupakan institusi lokal informal yang memiliki peran penting dalam pengelolaan bencana di KRB Gunung Kelud. Komunitas Jangkar Kelud berdiri tahun 2008 merupakan organisasi independen atau NGO yang lahir dari masyarakat lokal yang tinggal di sekitar Gunung Kelud. Institusi ini mewadahi relawan kebencanaan seperti relawan dari tim siaga desa di wilayah KRB Gunung Kelud, relawan dari ormas keagamaan, organisasi profesi (guru-guru) dan organisasi kepemudaan dari tiga wilayah Kabupaten yaitu Kediri, Blitar dan Malang. Hingga saat ini Komunitas Jangkar Kelud dimotori oleh Mbah Darmo sebagai ketua koordinator dari tiga wilayah administratif. Pengalamannya dalam penanganan bencana Gunung Kelud membuat Komunitas Jangkar Kelud menjadi salah satu intistusi lokal yang tangguh, mandiri dan mejadi andalan masyarakat di sekitar Gunung Kelud. Pengalaman berjejaring dengan berbagai organisasi kebecanaan di tingkat global (Lokal-Nasional-Internasional) seperti UNDP, FAO, Kappala, MPBI, Rekompak-Merapi, Jalin Merapi dan sebagainya menjadi rekam jejak yang sangat diperhitungkan aktor-aktor yang terlibat dalam peneglolaan bencana di KRB Gunung Kelud.

Sementara, institusi formal yang berperan dalam pengelolaan bencana di KRB Gunung Kelud Kabupaten Kediri antara lain pemerintah daerah dan istitusi terkait yaitu BPBD, kecamatan dan pemeritah desa. BPBD Kabupaten Kediri, meskipun memiliki legitimasi yang kuat sebagai institusi yang memiliki tugas dan kewenangan dalam penanggulangan bencana di satu sisi, namun menghadapi sejumlah hambatan di sisi yang lain. Meskipun Kabupaten Kediri termasuk salah satu daerah rawan bencana di Jawa Timur, namun keberadaan istitusi BPBD baru berdiri di lingkungan pemerintahan Kabupaten Kediri tahun 2015 melalui Perda No 2 Tahun 2015 Kabupaten Kediri. Sebagai institusi baru di lingkungan pemerintah daerah persoalan masih terbatasnya jumlah SDM dan kapasitas SDM aparatur sipil daerah dan satuan tugas pelaksana di lapangan 
masih sangat terbatas. Kondisi ini yang membuat BPBD menjadi sangat terbantu dengan keberadaan dan pengalaman Komunitas Jangkar Kelud yang terlebih dulu berkecimpung dalam penegelolaan bencana di KRB Gunung Kelud. Hal ini terungkap dari hasil eksplorasi di lapangan melalui in dept iterview bersama Bapak Dadik Rahardjo, Sie Pencegahan dan Kesiapsiagaan BPPD Kabupaten Kediri:

"BPBD Kabupaten Kediri ini institusi baru di lingkungan pemerintahan Kabupaten Kediri, terbentuk tahun 2015. Sudah pasti butuh penguatan institusi. Kami merasa sangat terbantu dengan Jangkar Kelud yang dimotori Mbah Darmo. Beliau punya pengalaman banyak dalam pengelolaan bencana di kawasan Gunung Kelud. Punya banyak jaringan. Mbah Darmo juga yang mengenalkan kami dengan dengan UNDP, FAO, UPN Yogyakarta dan bersama Jangkar Kelud kami menginisiasi pembetukan Forum Komunikasi Pengurangan Risiko Bencana di Kabupaten Kediri dengan melibatkan organisasi kemasayarakatan, orgaisasi keagamaan dan organisasi kepemudaan. (Sumber: in depth interview tanggal 17 September 2018).

Data empiris tentang keterlibatan masyarakat dalam pegelolaan bencana dapat dianalisis melalui respon dan kesiapsiagaan masyarakat dalam menghadapi erupsi Gunung Kelud tahun 2014. Erupsi Gunung Kelud yang terjadi pada tanggal 13-14 Februari 2014 telah menimbulkan dampak yang luas. Selain abu vulkanik yang menyebar hampir menyelimuti Pulau Jawa, material vulkanik seperti kerikil, batu dan pasir juga merusak bangunan dan lahan pertanian di wilayah Kabupaten Kediri, Blitar dan Malang. Berdasarkan data yang diperoleh dari BPBD Kabupaten Kediri (2017); di Kabupaten Kediri, terdapat 4 kecamatan terdampak erupsi Kelud
2014 yaitu kecamatan Puncu, Kepung, Ngancar, dan Plosoklaten. Empat wilayah ini merupakan daerah terdampak langsung, namun besaran dampak yang dirasakan masyarakat berbeda-beda. Kecamatan yang mengalami kerusakan paling parah akibat erupsi gunung Kelud yaitu Puncu dengan jenis kerusakan bagunan kategori berat mencapai 8.622 dan kategori sedang mencapai 5.466 unit. Dampak kerusakan rumah terparah sebagian besar dialami warga desa Besowo mencapai 1.842 unit. Kerusakan rumah kategori berat juga dialami warga kecamatan Puncu terutama warga desa Puncu dan Asmorobangun. Selain itu kerusakan rumah kategori berat juga dialami warga di kecamatan Kepung terutama di desa Kebon Rejo dan desa Kampung Baru. Sementara kerusakan sedang terjadi hampir di semua wilayah terdampak di empat kecamatan yaitu kecamatan Puncu, Kepung, Ngancar dan Plosoklaten. Meskipun menimbulkan kerusakan, namun tidak ada korban jiwa (zero victim) dalam proses evakuasi maupun dalam barak pengungsian. Hal ini menujukkan kesiapsiagaan masyarakat dalam menghadapi erupsi Gunung Kelud dengan dampak yang ditimbulkanya.

Pasca erupsi tahun 2014, keterlibatan masyarakat dalam pengelolaan bencana di kawasan Gunung Kelud adalah dengan terlibat aktif mengikuti kegiatan-kegiatan yang bertujuan untuk penaggulangan bencana (membangun kesadaran, kesiapsiagaa, pegurangan risiko bencana dan pencegahan dan mitigasi) baik yang diinisiasi oleh BPBD, Komunitas Jangkar Kelud, tokoh adat maupun dari anggota masyarakat. Salah satu bentuk keterlibatan masyarakat yang tinggal di sekitar Gunung Kelud Kabupaten Kediri seperti; Sugihwaras, Ngancar, Sempu, Wates, Kepung, Pojok dan Damarwulan dapat diamati dalam berbagai kegiatan-kegiatan yang diselenggarakan oleh BPBD 
bersama Komuitas Jangkar Kelud dalam membangun kesiapsiagaan dan mitigasi bencana. Berdasarkan dari data yang diperoleh melalui participant observation dengan 'sinau bareng' bersama Jangkar Kelud dan BPBD Kabupaten Kediri dalam kegiatan 'Peningkatan Kerjasama Antar Desa Dalam Penanggulangan Bencana" (Sister Village) tahun 2018.

Dalam kegiatan yang dilakukan selama 16 April-29 April 2018, masyarakat (warga yang tinggal di KRB Gunung Kelud; Desa Sempu, Pojok, Segaran-Wates, Besowo, Damarwulan-Kepung) sangat antusius mengikuti seluruh rangkaian kegiatan yang diselenggarakan BPBD, Jangkar Kelud dan fasilitator dari UNDP. Keterlibatan ini terlihat selama kegiatan pendidikan dan pelatihan berlangsung. Seperti yang disampaikan salah satu informan (Mas Sugeng, 32 tahun) salah satu warga dari desa Besowo, anggota tim siaga bencana (Tagana) yang mengikuti kegiatan pendidikan dan pelatihan 'Sister Village" di desa Besowo dan Desa Damarwulan Kecamatan Kepung tanggal 23-29 April 2018.

"Ya kegiatan seperti ini lho yang kami harapkan, kita sebagai warga yang mengalami langsung waktu Kelud meletus diajak 'rembugan', persiapannya seperti apa, diajak mikir kebutuhannya apa, fasilitas yang dimiliki apa, dan rencananya seperti apa. Jadi kalau sewaktu-waktu Kelud meletus lagi bisa siap-siap dan "ndak gendadapan" (Sumber: in dept interview, tanggal 25 April 2018).

Dengan metode 'sinau bareng', yang diterapkan fasilitator dari UNDP dan Jangkar Kelud, masyarakat yang mengalami langsung dampak erupsi Kelud 2014, diajak untuk mendefinisikan, mengidentifikasi kebutuhan pengungsi, melakukan assesment, merencanakan, dan memutuskan dalam membagu kerjasama melalui pembetukan desa bersaudara (sister village). Kegiatan ini merupakan upaya dalam mengembangkan mitigasi (pengurangan risiko bencana) dengan menempatkan pengungsi di desa bersaudara yang letaknya di luar Kawasan Rawan Bencana (KRB) Gunung Kelud, sehingga apabila bencana terjadi, masyarakat di KRB Gunung Kelud tidak panik, bisa melakukan evakuasi secara madiri karena sudah memiliki arah dan tujuan yang jelas kemana mereka harus mengungsi. Pola ini mengadopsi program sister village yang telah dikembangkan di KRB Gunung Merapi pasca erupsi tahun 2010. Pembentukan desa bersaudara ini bertujuan menyatukan dua pasang desa atau lebih dalam suatu hubungan yang dilembagakan. Dalam mempersiapkan penerapan program ini, desa penyangga turut bekerja sama. Hal ini dikarenakan fasilitas dan sarana prasarana pendukung pengungsian berada di desa penyangga, sehingga mereka juga turut berperan dalam penyediaannya. Pemenuhan kebutuhan dasar pengungsian seperti tempat penampungan, tempat logistik, dapur umum, dan tempat MCK (mandi, cuci, kakus) harus dipersiapkan dengan baik.

\section{Peran Tokoh-Tokoh Lokal}

Pengelolaan bencana yang dikembangkan institusi lokal di kawasan Gunung Kelud Kabupaten Kediri antara lain dapat dilihat dari peran pemimpin dan tokoh-tokoh lokal dalam pembentukan habitus siaga dan mengembangkan mitigasi berbasis komunitas lokal dalam menghadapi bencana. Upaya ini dilakukan sebagai langkah strategis dalam membangun kesiapsiagaan masyarakat dalam menghadapi bencana. Upaya ini dilakukan melalui mekanisme kelembagaan yang ada di tingkat lokal, dengan melibatkan seluruh pemangku kepentingan, 
termasuk pemimpin, intelektual, dan tokoh-tokoh lokal baik dari institusi pemerintah, tokoh adat, dan tokoh agama.

Mengikuti pemikiran Bourdieu (1977:72), bahwa habitus merupakan struktur yang distruktur oleh dunia sosial (structured structure). Habitus merupakan seperangkat struktur mental yang bertahan lama dan diperoleh melalui latihan berulang-ulang Habitus dilihat dalam diri agen yang kemudian terwujud dalam praktik kesiapsiagaan dalam konteks respons terhadap bencana. Untuk lebih memahami pelaksanaan latihan menghadapi bencana sebagai struktur dalam pembentukan habitus kesiapsiagaan. Dari hasil eksplorasi di lapangan peneliti menemukan bahwa pembetukan habitus siaga bencana dan pengembangan mitigasi di KRB Gunung Kelud Kabupaten Kediri dilakukan melalui kegiatan pendidikan dan pelatihan (lokal latih) dalam menghadapi bencana di kawasan lereng Gunung Kelud yang dilakukan Tim Siaga bencana desa (Sempu, Besowo) bersama Komunitas Jangkar Kelud. Gambar 3 menujukkan keikutsertaan agen dalam pelaksanaan menghadapi bencana di kawasan Gunung Kelud yang diselengagarakan oleh pemerintah daerah bersama komunitas "Jangkar Kelud" dalam pembentukan habitus siaga, membangun kesiapsiagaan dan mitigasi bencana di KRB Gunung Kelud Kabupaten Kediri.

Mekanisme mempertahankan tatanan sosial atau reproduksi sosial cenderung dominan dalam masyarakat. Institusi keluarga memegang peran yang menentukan dalam memelihara tatanan sosial, dalam reproduksi, tidak secara biologis, melainkan juga melalui pewarisan, pendidikan, investasi ekonomi, dan reproduksi sosial, artinya reproduksi struktur lingkup sosial dan hubungan-hubungan sosial. Selanjutnya reproduksi sosial dapat dijelaskan melalui berbagai strategi yang digunakan untuk mempertahankan dan mendapatkan berbagai bentuk modal. Pelaku akan berusaha mempertahankan atau menambah jenis dan besarnya modal. Usaha mereka diarahkan dalam rangka mempertahankan dan memperbaiki posisi sosial. Keluarga menjadi basis strategi pokok. Pertama meliputi strategi investasi biologis, strategi pewarisan, dan strategi pendidikan.

Institusi keluarga, sebagaimana dipikirkan Bourdieu (1994:142) menjadi tempat paling diinginkan bagi akumulasi modal dalam berbagai jenisnya dan tempat pewarisan antargenerasi. Keluarga adalah subjek utama strategi-strategi repoduksi. Demikian pula dalam pewarisan nilai-nilai budaya mitigasi dan siaga bencana antar generasi. Aktor-aktor yang terlibat dalam pengelolaan bencana di KRB Gunung Kelud menyadari dan mengakui bahwa keluarga menjadi tempat yang paling strategis untuk pewarisan nilai-nilai budaya mitigasi dan siaga bencana. Sehingga strategi sebagaimana digagas Bourdieu (1994:142) digunakan aktor-aktor yang terlibat dalam tata kelola bencana untuk mengembangkan budaya mitigasi dan siaga bencana di KRB Kelud. Strategi ini juga dikembangkan para pimpinan dari institusi pemerintah (BPBD, Kecamatan, Desa), tokoh agama, tokoh adat, tokoh pendidikan dan intelektual dan menjadikan keluarga sebagai salah satu strategi untuk mewariskan nilainilai yang mendukung dalam pengembangan budaya mitigasi bagi anak diterapkan.

Mengikuti pemikiran Bourdieu (1994) bahwa jika keluarga memegang peran penting dalam memegang dan menentukan tatanan sosial, maka keluarga bisa mejadi basis strategi utama dalam mengembangkan budaya mitigasi dan membangun kesiapsiagaan masyarakat dalam menghadapi bencana di kawasan Gunung Kelud. Pengalaman para 
informan dalam membangun budaya mitigasi dan kesiapsiagaan yang kuat dalam lingkup institusi keluarga memberikan kontribusi dalam pembentukan sikap dan perilaku (habitus) siaga bencana dalam masyarakat. Argumen ini diperkuat penuturan informan berikut ini.

"Saya ini seorang guru dan sejak 2008 aktif di Jangkar Kelud bersama Mbah Darmo. Menurut saya strategi membangun budaya mitigasi dan kesiapsiagaan masyarakat di KRB Gunung Kelud ini ya melalui dunia pendidikan. Tentu pendidikan dalam arti luas ya, mulai dari keluarga sampai ke sekolah-sekolah dan masyarakat. Pendidikan dalam keluarga pasti yang utama, karena transfer pengetahuan bisa secara langsung, orang tua otomatis jadi guru bagi anak-anaknya. Pengetahuan tentang bagaimana hidup di sekitar gunung Kelud, bagaimana karakteristik Gunung Kelud. Mengajarkan jangan hanya mau enaknya saja tinggal di sekitar Gunung Kelud karena lahan subur, nyaman, ekonomi berkembang, wisata alam Gunung Kelud berkembang, tapi anak-anak perlu diajarkan juga bagaimana kesiapan jika Gunung Kelud 'mbledhos', erupsi. Kalau sudah gedhe pasti sudah paham, tapi yang paling penting justru untuk anakanak seperti anak-anak TK, SD ini. Karena ini akan mempengaruhi sikap dan perilakunya nanti kalo sudah dewasa, nanti ilmunya bisa diwariskan pada keluarganya juga.”.

(In dept iterview, tanggal 26 April 2018 dengan Bu Mamik (Kepala Sekolah SDN I Besowo dan aktif dalam Komunitas Jangkar Kelud).

Pendapat serupa juga diungkap pakar gunungapi Mbah Rono (Dr. Surono), yang menyatakan pentingnya membangun budaya mitigasi sejak dini. Dalam Buku 'Belajar Membumi Bersama
Mbah Rono' karya Regina Safri (2015:34-35) Mbah Rono menyatakan bahwa"

"Teknologi secanggih apa pun, akhirnya menjadi percuma jika masyarakat di situ tak memiliki pendidikan dan kesadaran akan bencana alam. Pengalaman Gunung Merapi pada Oktober 2010, sudah dipasang 'system early warning', namun pada 25 Oktober masih saja ada yang tak mau mengungsi. Jadi apa artinya mengembangkan teknologi kalu manusianya tak mau belajar? Karena teknologi secanggih apapun tetap tak mau mereka patuhi. Itu makanya sekali lagi saya bilang pendidikan nomer satu. Untuk menghadapi bencana alam, manusialah yang harus belajar, bukan karena pengalaman. Manusialah yang wajib memiliki kesadaran, lalu kesiapan, kemauan untuk mau mengerti alam. Wong tentara mau perang dan bunuh orang aja perlu latihan dan belajar kok, apalagi ini menghadapi bencana alam. Saya takutnya tidak seтиa orang paham tentang kondisi alam kita..."

"Semestinya ada pendidikan dini. Mulai dari keluarga, dari bangku sekolah, sudah diajarkan muatan lokal tentang mengenal karakter alam kita. Para siswa dipaksa untuk mengetahui alam, setidaknya paham dan mengenal alam sekitar tempat tinggal. Karena wajib hukumnya tahu kondisi dan karakter alam tempat kita tinggal..."

Dalam pembentukan habitus siaga dan mitigasi bencana para pemimpin, tokoh lokal dan warga di kawasan Gunung Kelud melalui mekanisme institusinya masih kuat bersandar pada kearifan lokal dengan mengembangkan sikap hidup "Harmoni bersama Gunung Kelud”, dan 'Sitik Edang”. Bagi warga sekitar, Gunung Kelud merupakan bagian dari kehidupan sehari-hari yang tidak dapat dipisahkan secara sosio-kultural. Adanya kearifan lokal tentang Mitos Lembu Suro dan Ritual Larung Sesaji Kelud 
menjadi memori kolektif bagi Warga Lereng Kelud akan potensi ancaman di balik keberkahan yang dinikmati selama ini sekaligus dapat digunakan sebagai mitigasi kultural bagi masyarakat. Selain itu, adanya kepekaan dan kemampuan membaca tandatanda alam seperti suhu udara yang panas dan turunya hewan-hewan dari puncak Gunung Kelud menjadi pengetahuan lokal yang terus dikembangkan dalam pembentukan habitus dan menjadi modal bersama bagi institusi lokal. Temuan penelitian tentang kearifan lokal dalam pegelolaan bencana terutama dalam pembentukan habitus siaga dan mitigasi bencana bagi warga di KRB Gunung Kelud Kabupaten Kediri disajikan dalam tabel 3 .

Tabel 3. Kearifan Lokal Dalam Pengelolaan Bencana di KRB Gunung Kelud

\begin{tabular}{|c|c|c|}
\hline Kearifan Lokal & Makna & Sumber dan Perkembangannya \\
\hline $\begin{array}{l}\text { Mitos terkait Sumpah Lembu Syuro } \\
\text { "Blitar Dadi Latar, Kediri dadi Kali, } \\
\text { Tulungagug dadi Kedung" }\end{array}$ & $\begin{array}{l}\text { Makna: Sebagai mitigasi kultural. } \\
\text { Pengigat masyarakat Blitar, Kediri dan } \\
\text { Tulungagung, jika Gunung Kelud } \\
\text { menunjukkan tanda-tanda akan Erupsi. } \\
\text { Masyarakat mengungsi r untuk } \\
\text { keselamatan diri dan keluarga agar } \\
\text { terhindar dari dampak material yang } \\
\text { dilontarkan seperti batu, abu, dan lahar } \\
\text { panas dan lahar hujan. panasGunung } \\
\text { Kelud. }\end{array}$ & $\begin{array}{l}\text { Masyarakat Kediri-Blitar, ditemuka } \\
\text { dalam Buku Cerita Rakyat Jawa Timur. }\end{array}$ \\
\hline $\begin{array}{l}\text { Ritual Larung Sesaji Kelud setiap bulan } \\
\text { Syuro dalam penanggalan Jawa }\end{array}$ & 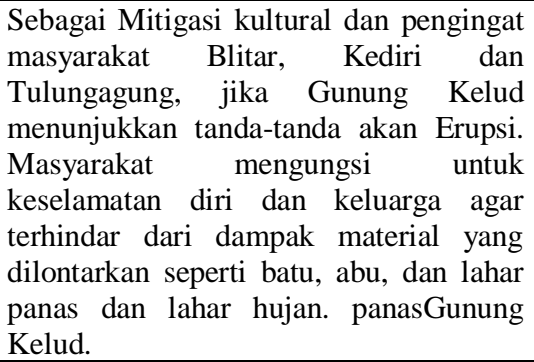 & $\begin{array}{l}\text { Dikembangkan masyarakat Lereng } \\
\text { Kelud, didukung Pemkab Kediri, BPBD, } \\
\text { tokoh masyarakat, tokoh agama, } \\
\text { relawan, budayawan dan komunitas } \\
\text { lokal. }\end{array}$ \\
\hline $\begin{array}{l}\text { Pembangunan Patung Lembu Syuro di } \\
\text { kawasan wisata Gunung Kelud }\end{array}$ & $\begin{array}{l}\text { Sebagai mitigasi fisik; } \begin{array}{r}\text { untuk } \\
\text { membangun ingatan sosial } \\
\text { (memory }\end{array} \\
\text { collective) masyarakat dalam melakukan } \\
\text { pencegahan dan pengurangan risko } \\
\text { bencana. }\end{array}$ & PemKab Kediri dan CSR Bank Jatim \\
\hline Sitik edang & $\begin{array}{l}\text { Sitik edang memiliki makna dan konsep } \\
\text { berbagi dan dalam etika kesetaraan } \\
\text { ekologis yaitu perlunya sikap dan } \\
\text { tindakan menghormati sejenak makluk } \\
\text { lain (biotik, nonbiotik) dalam hal ini } \\
\text { Gunung Kelud untuk bekerja. Setelah } \\
\text { selama ini memberikan keberkahan bagi } \\
\text { masyarakat sekitar bertahun-tahun } \\
\text { hingga puluhan tahun. Gunung Kelud } \\
\text { perlu waktu 1-3 bulan saja untuk } \\
\text { 'tandang gawe', miggirlah sejenak. }\end{array}$ & $\begin{array}{l}\text { Pak Dadik (Staf BPBD Sie Pencegahan } \\
\text { dan Kesiapsiagaan Kab. Kediri) } \\
\text { Sebagai ASN Daerah Kab Kediri dan } \\
\text { bertugas di BPBD sekaligus sebagai } \\
\text { Warga Kediri merasa memiliki } \\
\text { kewajiban moral untuk mengembangkan } \\
\text { nilai-nilai saling menghormati, saling } \\
\text { mengingatkan tentag prinsip hidup } \\
\text { saling berbagi dan saling menghormati } \\
\text { antara manusia dengan alam, dalam } \\
\text { konteks ini Gunung Kelud. }\end{array}$ \\
\hline Harmoni Bersama Kelud & $\begin{array}{l}\text { Sikap hidup yang perlu dikembangkan } \\
\text { oleh masyarakat yang tinggal di kawasan } \\
\text { Gunung Kelud, baik dalam kondisi } \\
\text { normal. maupu dalam kondisi sedang } \\
\text { beraktivitas. }\end{array}$ & $\begin{array}{l}\text { Dikembangkan oleh }{ }^{2} \text { Komunitas } \\
\text { Janngkar Kelud yang dimotori oleh } \\
\text { Mbah Darmo selaku koordiator }\end{array}$ \\
\hline
\end{tabular}

Sumber: sintesa dari wawancara dengan para Informan, 2018 
Dilema Dalam Ranah Pengelolaan Bencana Di KRB Gunung Kelud

Dalam menjalankan peranya dalam pembentukan habitus siaga dan pegembangan mitigasi becana di kawasan Gunug Kelud aktor-aktor dari institusi lokal menghadapi beberapa dilema. Hasil penelitian menunjukkan bahwa dilema yang dihadapi antara lain, di satu sisi pola pengelolaan bersifat yang bersifat egaliter terus dikembangkan oleh aktor dari BPBD Kabupaten Kediri, NGO Jangkar Kelud dan para Relawan, namun di sisi lain, sikap fatalis masih ada terutama terutama orangorang berusia tua yang masih kokoh dengan tradisi dan berorietasi ke masa lampau, tingkat pendidikan relatif rendah (SD/Tidak tamat SD). Sikap fatalis ini masih mewarnai pola peneglolaan bencana di wilayah KRB Kelud seperti yang ditemukan peneliti melalui wawancara dengan informan berikut ini.

"Sing angel niku nggih ngadepi tiyang-tiyang sepuh sing kekuh kalih tradisi, sing percayai hal-hal yang gaib-gaib itu. Maksud kulo hubunganipun kalih meletusnya Kelud lho nggih. Kita memang percaya tentang dunia gaib, tapi terkait meletusnya Kelud, masyarakat harus disadarkan, harus dipahamkan kalau Kelud meletus itu fenomena alam, dan cara kerja alam untuk mencari keseimbangan. Sehingga kita perlu mengenali tanda-tandanya. Wong kita memang tinggal di dekatnya kok. Jangan sampai karena kekehnya pada hal-hal yang gaib, mistis dapat membuat masyarakat terjebak pada hal-hal yang mistis, sampai kita kehilangan akal sehat dan membahayakan diri sendiri dan orang lain. Tapi kalau anak-anak sekarang lebih gampang menjelaskannya. Kasus Mbah Maridjan di Merapi sering saya gunakan untuk contoh perlunya mengatur (mengelola) keselamatan, perluya kita 'menyingkir' sejenak kalo Kelud mau 'tandang gawe'. Toh kita mau dipindah juga belum tentu mau, wong kita kadhung nyaman dengan enaknya tinggal di dekat Kelud.... (in dept interview dengan Mas Romy, Relawan Jangkar Kelud Desa Damarwulan Kecamatan Kepung tanggal 26 April 2018).

Dilema dalam ranah pengelolaan bencana di KRB Gunung Kelud, juga dialami institusi lokal seperti BPBD, Komunitas Jangkar Kelud dan Komuitas Siaga Bencana Desa. Hasil eksplorasi di wilayah studi menemukan beberapa dilema yang dialami aktor-aktor dari berbagai institusi lokal dalam proses pengelolaan bencana. Hasil identifikasi terkait dilema-dilema yang dialami institusi lokal dalam pegelolaa bencana tertuang dalam tabel Tabel 4 .

Tabel. 4. Dilema Yang Dialami Institusi Lokal Dalam Pengelolaan Bencana

\section{Di KRB Gunung Kelud}

\begin{tabular}{|c|c|}
\hline Tahap & Permasalahan \\
\hline Mitigasi & $\begin{array}{l}\text { 1. Cara pandang masyarakat terhadap bencana yang beragam } \\
\text { 2. Komitmen legislatif untuk mendukug pengembangan program mitigasi masih rendah } \\
\text { 3. Tumpang tindih kewenangan antar istansi/SKPD terkait } \\
\text { 4. Dukungan anggaran yang masih minim } \\
\text { 5. Masih terbatasnya desa-desa di KRB yang mengaplikasikan Sistem Informasi Desa (SID) } \\
\text { terkait data demografi, geografi dan sumber daya yag dimiliki. }\end{array}$ \\
\hline Kesiapsiagaan & $\begin{array}{l}\text { 1. Kegiatan pelatihan utuk membangun kesipasiagaan aparat dan masyarakat masih sebatas } \\
\text { program dan tidak mendapat jaminan untuk melakukan kegiatan secara berkelanjutan. } \\
\text { 2. Pengaturan tentang evakuasi (protap) untuk warga terdampak masih minim, dan sistem } \\
\text { 3. Infrastruktur seperti akses jalan untuk jalur evakuasi belum memadai } \\
\text { 4. Sistem anggaran kurang mendukung }\end{array}$ \\
\hline Respon & $\begin{array}{l}\text { 1. Hambatan koordinasi dan komunikasi dengan instansi terkait } \\
\text { 2. Pemanfaatan teknologi informasi belum optimal }\end{array}$ \\
\hline
\end{tabular}




\begin{tabular}{|c|c|}
\hline & $\begin{array}{l}\text { 3. Hambatan dalam distribusi logistik karena infrastruktur yang tidak mendukung, keterbatasan } \\
\text { SDM } \\
\text { 4. Minimnya pengetahuan, pengalamana dan keahlian aparat dan relawan dalam penanggulangan } \\
\text { bencana }\end{array}$ \\
\hline Pemulihan & $\begin{array}{l}\text { 1. Keterbatasan anggaran, belum adanya payung hukum utuk pelaksanaan pemulihan dan } \\
\text { 2. Miimnya kompetensi (keahlian) dalam penanganan bencana } \\
\text { 3. Minimnya koordinasi dan komunitas serta hambatan struktural lainnya (pemerintah daearah- } \\
\text { pemerintah pusat) }\end{array}$ \\
\hline
\end{tabular}

Sumber: data primer hasil in dept interview dengan informan, 2017

Pengelolaan bencana sebagaimana yang diamanahkan dalam UU No 24 Tahun 2007 tentang Penanggulangan Bencana dan PP No 21 Tahun 2008 tentang Pedoman Penyelenggaan Penanggulangan Bencana di Indonesia melalui beberapa tahap yaitu; mitigasi, kesiapsiagaan, respons, dan pemulihan (Bevaola, 2014: 21). Dilema-dilema yang dihadapi institusi lokal dalam pengelolaan bencana di kawasan Gunung Kelud Kabupaten Kediri pasca erupsi tahun 2014 antara juga ditemukan dalam berbagai tahapan. Dalam tahap mitigasi; adanya cara pandang masyarakat yang beragam terhadap bencana berimplikasi pada sikap dan respon yang beragam pula terhadap bencana. Ada yang memandang bencana sebagai 'takdir Tuhan', ' bencana sebagai musibah', 'bencana berhubungan dengan hal-hal yang ghaib' dan bencana sebagai 'ujian'. Dari sisi kelembagaan, komitmen legislatif untuk mendukung pengembangan program mitigasi masih rendah, adanya tumpang tindih kewenangan antar instansi/SKPD terkait serta dukungan anggaran yang masih minim.

Dalam tahap kesiapsiagaan, dilema yang dihadapi antara lain; Kegiatan pelatihan utuk membangun kesipasiagaan aparat dan masyarakat masih sebatas program dan tidak mendapat jaminan untuk melakukan kegiatan secara berkelanjutan, Pengaturan tentang evakuasi (protap) untuk warga terdampak masih minim, dan sistem peringatan dini tidak memadai; Infrastruktur seperti akses jalan untuk jalur evakuasi belum memadai dan sistem anggaran kurang mendukung.

Dalam tahap respon, dilema yag dihadapi antara lain; Hambatan koordinasi dan komunikasi dengan instansi terkait; Pemanfaatan teknologi informasi belum optimal; hambatan dalam distribusi logistik karena infrastruktur yang tidak mendukung, keterbatasan SDM; dan minimnya pengetahuan, pengalamana, dan keahlian aparat dan relawan dalam penanggulangan bencana. Sementara dalam tahap pemulihan, dilema yang dihadapi antara lain; Keterbatasan anggaran, belum adanya payung hukum untuk pelaksanaan pemulihan dan minimnya kompetensi (keahlian) dalam penanganan bencana, serta minimnya koordinasi dan komunitas serta hambatan struktural lainnya (pemerintah daerahpemerintah pusat).

\section{Kesimpulan}

Dalam pengelolaan bencana ada beberapa tahapan yang dilakukan antara lain; prevention/pencegahan, preparednes/kesiapsiagaan, reaction/tanggap darurat, dan recovery/pemulihan. Pasca erupsi tahun 2014, pengelolaan bencana di kawasan Gunung Kelud Kabupaten Kediri lebh diarahkan pada upaya pencegahan (mitigasi) dan membangun kesiapsiagaan masyarakat dalam menghadapi bencana. Upaya ini dilakukan dengan melibatkan berbagai pihak terutama institusi lokal yang ada di Kabupaten Kediri. Hasil penelitian menujukkan bahwa peran institusi lokal dalam 
pengelolaan bencana dalam pembentukan habitus siaga dan mitigasi bencana antara lain: institusi pemerintah yang meliputi Badan Penanggulangan Bencana Daerah (BPBD) Kabupaten Kediri, Komunitas Jangkar Kelud (NGO); Komuitas Siaga Bencana dari Ormas Keagamaan (Pemuda NU, Muhammadiyah, GKJW, Hindu), tokoh agama, tokoh adat dan Komuitas Siaga Bencana Desa di sekitar Gunung Kelud (Desa Sempu, Sugihwaras, Ngacar, Pojok, Segaran, Besowo, dan Damarwulan).

Dalam pengembangan mitigasi bencana di kawasan Gunung Kelud Kabupaten Kediri strategi yang ditempuh atara lain melalui pendidikan dan pelatihan di semua jenjang sekolah mulai TK sampai SLTA serta membangun kerjasama antar institusi yaitu dengan mengembangkan Desa Bersaudara (Sister Village) yaitu mempersaudarakan antara desadesa pengungsi dan desa penyangga di kawasan rawan bencana Gunung Kelud. Dalam pembentukan habitus siaga dan mitigasi bencana para pemimpin, tokoh lokal dan warga di kawasan Gunung Kelud melalui mekanisme institusinya masih kuat bersandar pada kearifan lokal dengan mengembangkan sikap "Hidup bersama Gunung Kelud", "Harmoni bersama ancaman" dan 'Sitik Edang”. Bagi warga sekitar, Gunung Kelud merupakan bagian dari kehidupan sehari-hari yang tidak dapat dipisahkan secara sosiokultural. Adanya kearifan lokal tentang Mitos Lembu Suro dan Ritual Larung Sesaji Kelud menjadi memori kolektif bagi Warga Lereng Kelud akan potensi ancaman dibalik keberkahan yang dinikmati selama ini sekaligus dapat digunakan sebagai mitigasi kultural bagi masyarakat. Selain itu, adanya kepekaan dan kemampuan membaca tanda-tanda alam seperti suhu udara yang panas dan turunya hewan-hewan dari puncak Gunung Kelud menjadi pengetahuan lokal yang terus dikembangkan dalam pembentukan habitus dan menjadi modal bersama bagi institusi lokal.

\section{Daftar Pustaka}

Arifin \& Chusairi 2015, Pengurangan Risiko Bencana Berbasis Komunitas di Daerah Terdampak Erupsi Kelud, Jurnal Psikologi Kepribadian dan Sosial Vol. 04 No. 02, Agustus 2015.

Atkinson, P., Coffey, A., Delamont, S., Lofland, J. and Lofland, L. 2001. Handbook of

Ethnography, London: Sage.

Arsita Devy, Gaby Stefani, dkk, 2017,

Pengembangan Pariwisata Kelud Pasca Erupsi

Tahun 2014, Jurnal Administrasi Publik (JAP), Vol.3, No. 1, Hal.2077-2083| 2082.

Bevaola Kusumasari, 2014, Manajemen Bencana dan Kapabilitas Pemerintah Lokal, Penerbit Gava Media Yogyakarta.

Bourdieu, 1986 Distingtion: A Social Critique of The Judgement of Taste: Routledge \& Kegan Paul L.td, London.

Bourdieu, 1994 “La Distingtion, Critique Sociale du Jugement" (1979), by Les Edition de Minuit, Paris dan diterbitkan dalam bahasa Inggris pertama tahun 1986 dengan judul: "Distingtion: A Social Critique of The Judgement of Taste:, Routledge \& Kegan Paul L.td, London.

Denzin, Norman and Lincoln, Yvonna. 2009.

Handbook of Qualitative Research. Thousand Oaks, CA: Sage.

Harker, Richard, Cheelen Mahar \& Chris Wilkes, 2009, (Habitus X Modal) + Ranah= Praktik:

Pengantar Paling Komprehensif Kepada

Pemikiran Pierre Bourdieu, Penerbit, Jalasutra, Yogyakarta. 
Humaidi, Alie, 2015, "Penanganan Bencana Berbasis Perspektif Hubungan Antar Agama dan Kearifan Lokal yang dimuat dalam Analisa Journal of Social Science and Religion, Desember 2015, Vol.22 o0.02.

Indiyanto, Agus, Arqom Kuswanjono (ed), 2012, Respons Masyarakat Lokal Atas Bencana: kajian Integratif Ilmu, Agama dan Budaya, Penrbit Mizan, Bandung.

Kelman \& Mother, 2008, “Living with Volcanoes:

The Sustainable Livelihoods approach for volcano-related opportunities", dalam Journal of Volcanologi and Geothermal Research, 172, 189-198. 2008.

KOMPAS, 14 Desember 2016, "Kaleidoskop 2016: Lima Bencana Besar di Indonesia”

Lalone, Mary, 2012, “Neigbour Helping Neigbour: An Examination of Social Capital mobilization process for community resilence to enviroment disasters', dalam Journal of Aplaid Social, SAGE Publication.

Pramono, Rudy, 2016, "Perspektif Sosiologis Dalam Penanggulangan Bencana", Jurnal Masyarakat \& Budaya, Tahun 2016 Vol. 18 No. 1.

Ritzer, George, 2014, Teori Sosiologi Modern, Penerbit Kencana Prenadamedia, Jakarta. Safri, Regina, 2015, Belajar Membumi Bersama Mbah Rono: Memahami Gunung Api, Gempa
Bumi, dan Fenomena Alam di Infonesia, Galangpress, Yogyakarta.

Sartohadi, dkk (2014), Kajian Strategi Penghidupan Masyarakat di areal Gunungapi Kelud Pasca Erupsi Tahun 2014: Studi kasus di Pandansari dan Puncu, dalam Bunga Rampai Penelitian; Pengelolaan Kegunungberapian Kelud pada Periode Krisis Erupsi 2014, ed Junun Sartohadi dkk, Penerbit Pustaka Pelajar.

Sirimorok, Nurhady, 2013, “Kajian Kebencanaan Dan Ekologi Politik", dalam JURNAL

WACANA: EKOLOGI POLITIK: Bencana dan Perubahan Iklim, no 29/Tahun XV/ 2013, Penerbit, Insist ISSN: 1410-1298.

Smith, Oliver \&, Susanna Hoffman, 2004; Theorizing Disaster: Nature, power and Culture dalam Catastrophe \& Culture: The Anthropology of Disaster, Santa FE NM: School of American Research Press.

Wisner, P. Blaiki, Canon, I. Davis, 2004, At Risk: natural hazardd, People's, Vulnarability and Disasters, London and New York, Routledge. World Risk Report 2012, “Integrated Drought Management Programme, akses internet www.goegle//world-risk-report-2012

UU RI No 24 Tahun 2007 Tentang Penaggulangan Bencana. 